\title{
ANÁLISE EXPLORATÓRIA DOS DADOS CLIMÁTICOS E SUA INFLUÊNCIA NO Aedes aegypti, NO MUNICÍPIO DE CHAPECÓ/SC: RESULTADOS PARCIAIS
}

\author{
EXPLORATORY ANALYSIS OF CLIMATE DATA AND ITS INFLUENCE ON Aedes aegypti, IN \\ CHAPECÓ / SC: PARTIAL RESULTS
}

\author{
Cleusa Matiola \\ Discente do Mestrado Clima e Ambiente - IFSC \\ cleusamatiola@gmail.com \\ Eduardo Augusto Werneck Ribeiro \\ Docente do Mestrado Tecnologia e Ambiente - IFC \\ Docente do Mestrado Clima e Ambiente - IFSC \\ eduardo.ribeiro@ifc.edu.br
}

\begin{abstract}
RESUMO
A dengue é uma doença viral que vem colocando em risco parte da população do mundo. $O$ vírus é transmitido pelo Aedes aegypti, também transmissor do zika vírus e da febre chikungunya. O número de $A$. aegypti é significativo em Santa Catarina ao longo dos anos. As variações climáticas contribuem para 0 aumento do vetor, porém as condições socioeconômicas da população e a ação antrópica também influenciam. O objetivo deste estudo é uma análise exploratória das variáveis climáticas e possíveis correlações com o aumento de número de mosquitos em Chapecó/SC. Para isto, foi realizado modelagem estatística do número de $A$. aegypti, disponibilizados pela Diretoria de Vigilância Epidemiológica de Santa Catarina (DIVE), com distribuição da precipitação, médias de temperatura mínimas e máximas com recorte diário, entre 2010 e 2017, fornecidos por Modern Era Retrospective-Analysis For Research and Applications (MERRA2) da NASA. A pesquisa se mostrou promissora, os dados de MERRA2, trazem uma escala temporal que possibilitaram o estudo do clima com a proliferação do mosquito, tendo em vista que nem toda cidade conta com estação meteorológica. Este trabalho apresenta resultados parciais da pesquisa ainda em desenvolvimento, no programa de mestrado profissional Clima e Ambiente do Instituto Federal de Santa Catarina (IFSC).
\end{abstract}

Palavras-chave: Aedes aegypti. Clima. MERRA2.

\begin{abstract}
Dengue fever is a viral disease that is endangering the world's population. The virus is transmitted by the mosquito Aedes aegypti, now also transmitting the virus zika and chikungunya fever. The number of $A$. aegypti mosquitoes is significant in Santa Catarina over the years. The climatic variations contribute to the increase, however the socioeconomic conditions of the population and the anthropic action also influence in the proliferation of the vector. The objective of this study is an exploratory analysis of the climatic variables and their possible correlations with the increase in the number of mosquitoes in the municipality of Chapecó/SC. For this, a statistical modeling of the number of $A$. aegypti, made available by the Director of Epidemiological Surveillance of Santa Catarina (DIVE), with the distribution of precipitation, minimum temperature averages and maximum temperature averages with daily 2010 to 2017, provided by Modern Era Retrospective Analysis for Research and Applications (MERRA2) of the National Aeronautics and Space Administration (NASA). The research was promising, since the data from MERRA2, bring a time scale that made possible the study of the climate with the mosquito $A$. aegypti proliferation, considering that not every city has a meteorological station. This paper presents partial results of the research still under development, in the professional program Climate and Environment of the Federal Institute of Santa Catarina (IFSC).
\end{abstract}

Keywords: Aedes aegypti. Climate. MERRA2.

Recebido em: 13/10/2019

Aceito para publicação em: 11/11/2019

Artigo apresentado IX Simpósio Nacional de Geografia da Saúde, Blumenau, SC, 2019. 


\section{INTRODUÇÃO}

A dengue é uma doença viral que rapidamente se espalhou pelo mundo, nos últimos anos. Estima-se que entre 50 a 100 milhões de pessoas se infectam anualmente, em mais de 100 países, colocando em risco quase metade da população mundial (WHO, 2018). É causada por um arbovírus do gênero Flavivirus transmitida pelo Aedes aegypti, no Brasil, geralmente de caráter epidêmico, atingindo um número muito grande de pessoas. A transmissão se dá pela picada do mosquito fêmea com vírus, que se infecta picando pessoas doentes. Além do $A$. aegypti ser o mosquito responsável pela transmissão dos vírus da dengue no Brasil e nas Américas, também é responsável pela transmissão da febre do zika vírus, febre de chikungunya e febre amarela (DIVE, 2018b), tornando-se assim, um vetor que necessita de cuidados e controle.

A situação epidemiológica da dengue no Brasil, nos últimos dez anos, vem sendo caracterizada pelo número crescente de casos graves e óbitos. Além dos novos desafios impostos pela circulação dos vírus da febre de chikungunya e zika, cujos sintomas são parecidos com os da dengue, e fazem com que o tema se torne ainda mais importante (BRASIL, 2016).

Considerado um país tropical, por estar situado particularmente em zonas de latitudes baixas, nas quais prevalecem os climas quentes e úmidos, com temperaturas médias em torno de $20^{\circ} \mathrm{C}$, o Brasil torna-se suscetível à dengue em função de diversos condicionantes: alterações climáticas, mudanças globais, variabilidade do clima. Esses fatores, entre outros, contribuem expressivamente para a proliferação e desenvolvimento do $A$. aegypti - vetor do vírus (VIANA, 2013).

Apesar das contradições entre as associações entre $A$. aegypti, dengue e estações chuvosas, há um consenso de que a temperatura climática está correlacionada às infestações por este mosquito. Nos meses mais quentes do ano é que ele atinge o clímax reprodutivo e a taxa de metabolismo do vetor aumenta, abreviando seu ciclo evolutivo em até oito dias, ou prolongando-o até vinte e dois dias nos meses frios (CÂMARA, 2009).

Analisando os índices de precipitação e temperatura, é possível notar que há uma relação dos índices climáticos com o A. aegypti. É no final do período chuvoso, que ocorrem os melhores ambientes para proliferação desse mosquito, pois o acúmulo de água em recipientes artificiais, nos grandes centros urbanos, serve de criadouro ao mosquito (SILVA, 2007). A intermitência da chuva permite que os recipientes não extravasem como em dias de chuva contínua, permitindo a evolução do agente. É por isso que os recipientes artificiais são seus criadouros preferenciais, tanto os abandonados pelo homem a céu aberto e preenchidos pelas águas das chuvas, como aqueles utilizados para armazenar água para uso doméstico. Correspondem aos criadouros mais comuns: pneus, latas, vidros, cacos de garrafa, pratos de vasos e xaxins, vasos de cemitério, caixas d'água, tonéis, latões e cisternas abertas ou semiabertas, lagos artificiais, piscinas e aquários abandonados. Há proliferação de $A$. aegypti em água acumulada em locais (recipientes) principalmente sombreados e de fundo ou paredes escuras. O mosquito também tem sido observado, criando-se em recipientes naturais como bromélias usadas para ornamentação, buracos em árvores, escavação em rocha e bambus (CONSOLI e OLIVEIRA, 1994).

Com maior quantidade de criadouros surgidos pela ação antrópica, os núcleos urbanos são locais que oferecem melhores condições para ocorrência e sobrevivência do vetor. A urbanização sem a devida estrutura de saneamento possivelmente influencia na densidade e dispersão ativa do mosquito (RIBEIRO, 2006).

O mosquito é totalmente adaptado ao ambiente urbano, pois acha junto aos domicílios as condições necessárias para o seu desenvolvimento, que ocorre em águas acumuladas em recipientes que na maioria são usados pelo homem, por isso as condições socioambientais também são favoráveis à proliferação do vetor transmissor da dengue (SILVA, 2007). Nestes ambientes eles encontram fatores fundamentais para sua ocorrência: humanos, vírus, vetor e principalmente as condições políticas, econômicas e culturais que formam a estrutura que permite a reprodução e o estabelecimento da cadeia de transmissão (HINO, 2007).

O vetor sobrevive em baixa densidade durante os meses menos favoráveis em termos climáticos, apontando a relevância da manutenção das ações de vigilância e controle do vetor durante todo o ano (VIANA, 2013).

Portanto, há de se considerar múltiplos fatores condicionantes e determinantes que favorecem o aumento do número de mosquitos, como: temperatura, sazonalidade, comportamento do vetor, aspectos socioculturais e imunológicos da população. A pluviosidade não é fator determinante ao 
desaparecimento do mosquito porque não depende exclusivamente dos criadouros que surgem com o período chuvoso. O $A$. aegypti mantém o ciclo de vida no período seco, através de criadouros artificiais permanentes, como caixas d'água e caixas de passagem do sistema hidrossanitário (SOUZA, 2010).

A partir da revisão bibliográfica indicada, as condições climáticas não são determinantes na proliferação do mosquito causador da dengue. Ela pode ser considerada um fator agravante na situação, pois podem existir as condições climáticas ideais para a proliferação do mosquito, mas se não houver criadouros, o mosquito não sobreviverá e nem conseguirá se reproduzir.

As condições socioambientais são a maior responsável pelo aumento no número de casos de dengue. O clima exerce influência na proliferação da dengue, mas as maiores influências são dos condicionantes sociais que o homem cria, ao jogar lixo em terrenos baldios, ao deixar vasos com água acumulada, descartáveis, pneus, latas, garrafas, entre outros materiais com possibilidade de acúmulo de água da chuva (SILVA, 2007).

Uma das ferramentas pensadas para fortalecer as ações de prevenção e combate ao mosquito da dengue é o uso de indicadores, sobretudo os que possuem uma abordagem quali-quantitativa, pois, eles permitem retratar o panorama desta infestação relacionando-a aos fatores ambientais, econômicos e sociais possibilitando assim, o conhecimento mais aprofundado dos produtos e processos histórico, econômico, social, ambiental e de saúde que criaram condições propícias para a ampla disseminação desse vetor.

Graves problemas de saúde pública, como a infestação do mosquito da dengue, necessitam de ações dinâmicas e por vezes inter e transdisciplinares para fortalecer a atuação da Vigilância Epidemiológica, aumentando sua capacidade de antever os riscos, evitando a instalação de surtos da doença, aprimorando formas de controle do vetor e melhorando os condicionantes sociais e ambientais (FEITOSA, 2015).

Segundo o LIRAa - Levantamento de Índice Rápido para o A. aegypti, o município de Chapecó/SC vem apresentando alto risco de infestação do mosquito (DIVE, 2018a). Mesmo com os números expressivos, ainda se discute sobre quais estratégias são efetivas para o controle da dengue. Identificar qual é a causa do aumento de número de $A$. aegypti nas especificidades de cada região, é essencial para se discutir as estratégias eficientes de atuação e combate aos criadouros. Braga e Valle (2007) já apontavam para a necessidade de maiores investimentos em metodologias adequadas, para sensibilizar a população sobre a necessidade de mudanças de comportamento que objetivem o controle do vetor.

Várias bibliografias contribuem para o conhecimento sobre a doença e sobre o mosquito, porém, se faz necessário um diagnóstico sobre as áreas de maiores focos e indicadores que apontem os fatores que influenciam a proliferação do mosquito, aprimorando formas de controle do vetor, melhorando/sanando os condicionantes.

Nesse contexto, técnicas de avaliação da sazonalidade e a espacialidade, tem se tornado tendência e são abordagens potenciais para compreender o quadro de evolução, distribuição geográfica, como também para o entendimento e vigilância da dengue (FERREIRA, 2017). Para as regiões que possuem escassez de estações meteorológicas, problema ainda frequente em nosso país, o uso de dados por sensoriamento remoto é uma excelente alternativa para aquisição de dados de temperatura e do acumulado de precipitação (LIMA, 2018).

Neste sentido, uma alternativa é a manipulação dos dados do projeto Modern-Era Retrospective Analysis for Research and Applications (MERRA2) ${ }^{2}$ do Global Modeling and Assimilation Office (GMAO) da National Aeronautics and Space Administration (NASA). Esse banco de dados do satélite atmosférico GOES oferece um repositório de informações climáticas desde 1979.

MERRA2 é a mais recente reanálise atmosférica da era moderna de satélites produzida pelo GMAO. Ele fornece um reprocessamento consistente de observações meteorológicas, abrangendo um segmento estendido de registros de dados históricos, permitindo a produção de conjuntos de dados em grade para uma ampla gama de variáveis, incluindo aquelas não observadas diretamente, fornecendo uma análise climática completa, quase em tempo real. Pretende ser um marco de desenvolvimento para uma futura análise Integrada do Sistema Terrestre (IESA), (GELARO et al,

2 https://gmao.gsfc.nasa.gov/reanalysis/MERRA-2/ , acesso em 24 nov. 18. 
2017). Os dados de reanálise se tornaram essenciais para as pesquisas atmosféricas e monitoramento de variações climáticas.

Neste sentido, o objetivo deste trabalho é fazer uma análise exploratória da relação dos fatores climáticos (temperatura e precipitação), com o mosquito $A$. aegypti no município de Chapecó/SC. Ressalta-se que este trabalho é derivado de um projeto que ainda está em curso e que futuramente, os dados climáticos e os dados de $A$. aegypti serão analisados com os socioeconômicos do IBGE (CENSO, 2010) para identificar possíveis indicadores que influenciam na existência do mosquito, visando contribuir com a redução da infestação e o controle da doença no município.

\section{METODOLOGIA}

\section{Área de Estudo}

O estudo foi realizado no município de Chapecó (Figura 1), centro urbano, localizado no extremo oeste do estado de Santa Catarina, e apontado pelo Boletim Epidemiológico $n^{\circ}$ 05/2019 da Vigilância entomológica do Aedes aegypti e situação epidemiológica de dengue, febre de chikungunya e zika vírus em Santa Catarina (DIVE, 2019), como município com alto risco de infestação de A. aegypti.

Figura 1: Localização do município de Chapecó/SC

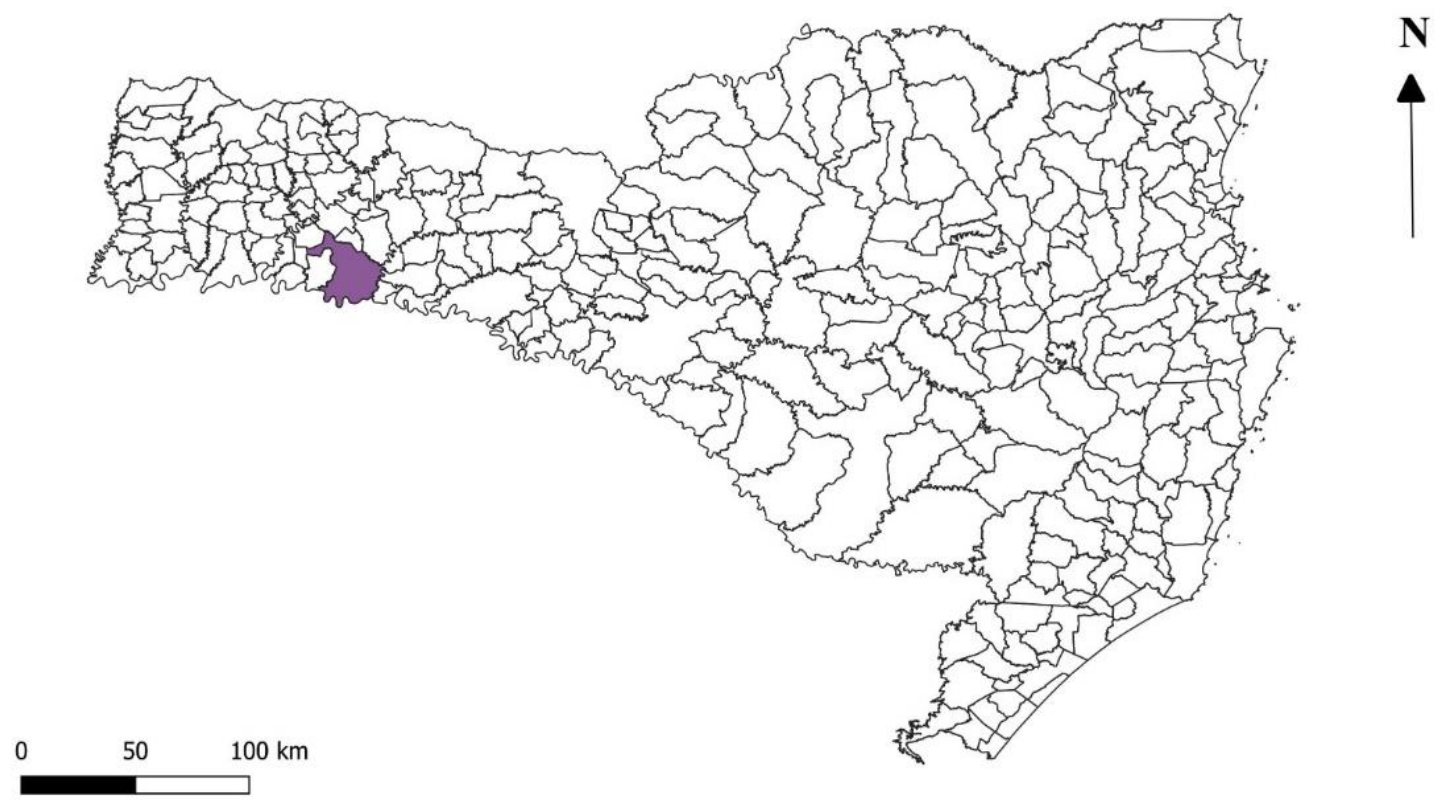

Fonte: IBGE, 2019.

\section{Dados e Métodos}

Para o desenvolvimento desta pesquisa foi necessário a aquisição de dados do mosquito $A$. aegypti e dados de temperatura e precipitação, referentes aos fatores climáticos.

Os dados referentes ao $A$. aegypti foram disponibilizados pelo banco de dados da DIVE. Foram utilizados dados dos registros diários de coleta do mosquito, classificados como: a) ovos; b) formas aquáticas (larvas e pupas); c) formas adultas.

Para as análises da influência dos fatores climáticos foram utilizados dados disponibilizados pelo produto de reanálise MERRA2, no formato NetCDF4. Através do software de visualização GrADS (Grid Analisys and Display System) foram selecionados dados diários de temperatura média mínima (TMIN), temperatura média máxima (TMAX) e precipitação (PREC), no período de 2010 a 2017, inicialmente disponibilizados em pontos de grade com resolução de $1 \times 1$ graus de lat/lon, interpolados para o município de Chapecó (27.07WS). Os dados de temperatura foram convertidos da unidade Kelvin para graus Celsius. 
Esses dados fazem parte de um conjunto de reanálises que possui uma alta resolução espacial de $0.5^{\circ}$ de Latitude por $0.625^{\circ}$ longitude, com 42 níveis verticais de pressão desde a superfície da Terra até a estratosfera. São calculados na mesma resolução espacial que o modelo atmosférico usando um algoritmo variacional tridimensional, com ciclos de atualização de 6 horas, e foi gerada utilizando o sistema global de assimilação de dados da NASA, com ênfase na estimativa do ciclo hidrológico e uma vasta variedade de informações meteorológicas (PENNA, 2018).

Para os estudos aqui realizados, foram utilizados os dados referentes ao município de Chapecó, para o período de 2010 a 2017. A DIVE disponibiliza dados de registros diários, referente a captura de formas do mosquito, a partir do ano de 2010.

Para a análise e interpretação dos dados, foi realizada modelagem estatística de:

a) Número de $A$. aegypti em séries históricas, agrupados por ano, por semana epidemiológica ${ }^{3}$, por estações do ano ${ }^{4}$, sobrepostos em gráficos para comparação.

A semana epidemiológica (SE) é uma distribuição temporal que permite a comparabilidade dos dados com padronização internacional. São contadas de domingo a sábado. A primeira semana do ano é aquela que contém o maior número de dias de janeiro e a última a que contém o maior número de dias de dezembro 5 .

b) Fatores climáticos com a distribuição dos dados diários da TMIN, TMAX e PREC em séries históricas, sobrepostos em gráficos.

c) Número de $A$. aegypti (larvas e pupas), TMIN, TMAX, PREC, agrupados por estações do ano, sobrepostos em um único gráfico para comparação da evolução populacional e a relação com os fatores climáticos.

Também foi utilizado o coeficiente de Spearman para avaliar a correlação entre as estações do ano com as TMAX e TMIN, PREC e números de $A$. aegypti notificados.

Este estudo atendeu as determinações da Resolução 466/2012 da Comissão Nacional de Ética e Pesquisa (CONEP) e foi previamente aprovado pelo Comitê de Ética em Pesquisa (CEP), na Unidade Central de Educação FAEM Faculdade (UCEFF), sob o parecer número 3.022.307.

\section{RESULTADOS E DISCUSSÃO}

Os resultados são avaliados em dois momentos. O primeiro, onde se observa a dinâmica temporal (meses e estações do ano) e no segundo, os resultados das correlações entre a PREC, TMIN e TMAX.

No período de 2010 a 2017, a DIVE registrou 70.256 ovos, 30.547 formas aquáticas (larvas e pupas) e 46 formas adultas do mosquito A. aegypti no município de Chapecó/SC.

Apenas nos anos de 2013 e 2014 foram registradas formas do mosquito na fase de ovos, com números elevados, principalmente em 2014. Após o município ser considerado infestado, a DIVE determinou a desinstalação das ovitrampas ${ }^{6}$, justificando a ausência de registro de ovos do mosquito nos anos seguintes, passando a utilizar o LIRAa e a inspeção de pontos estratégicos para o monitoramento. Transferindo assim, os esforços da vigilância epidemiológica para estratégias de combate, controle e prevenção do vetor (SALVI, 2018).

Em todos os anos estudados foram registradas formas aquáticas do $A$. aegypti. A flutuação populacional de larvas e pupas (Figura 2), apresentou crescimento ao longo da série histórica, com pico mais elevado no ano de 2013, somando o total de 7.820 larvas e pupas.

Houve um aumento significativo do número de $A$. aegypti encontrados no ano de 2013 , em relação ao ano anterior e a partir de então, percebe-se a ocorrência de menores números de mosquitos nos outros anos. Segundo Salvi (2018), a mudança de estratégia no monitoramento do vetor adotada pelo

3 http://portalsinan.saude.gov.br/calendario-epidemiologico, acesso em jan. 19.

4 http://www.iag.usp.br/astronomia/inicio-das-estacoes-do-ano, acesso em dez. 18.

5http://www.adapar.pr.gov.br/arquivos/File/GSA/EPIDEMIOLOGIA/Calendario semanas epidemio 2018.pdf, acesso em 6 fev. 19.

6 Tipo de armadilha utilizada para a captura de ovos de $A$. aegypti. 
Plano Municipal de Controle da Dengue (PMCD), após orientação da DIVE, explica a redução dos números nos anos de 2015 e 2016.

Figura 2: Flutuação populacional anual das formas aquáticas (larvas e pupas) de $A$. aegypti, registrados pela DIVE no município de Chapecó, entre 2010 a 2017

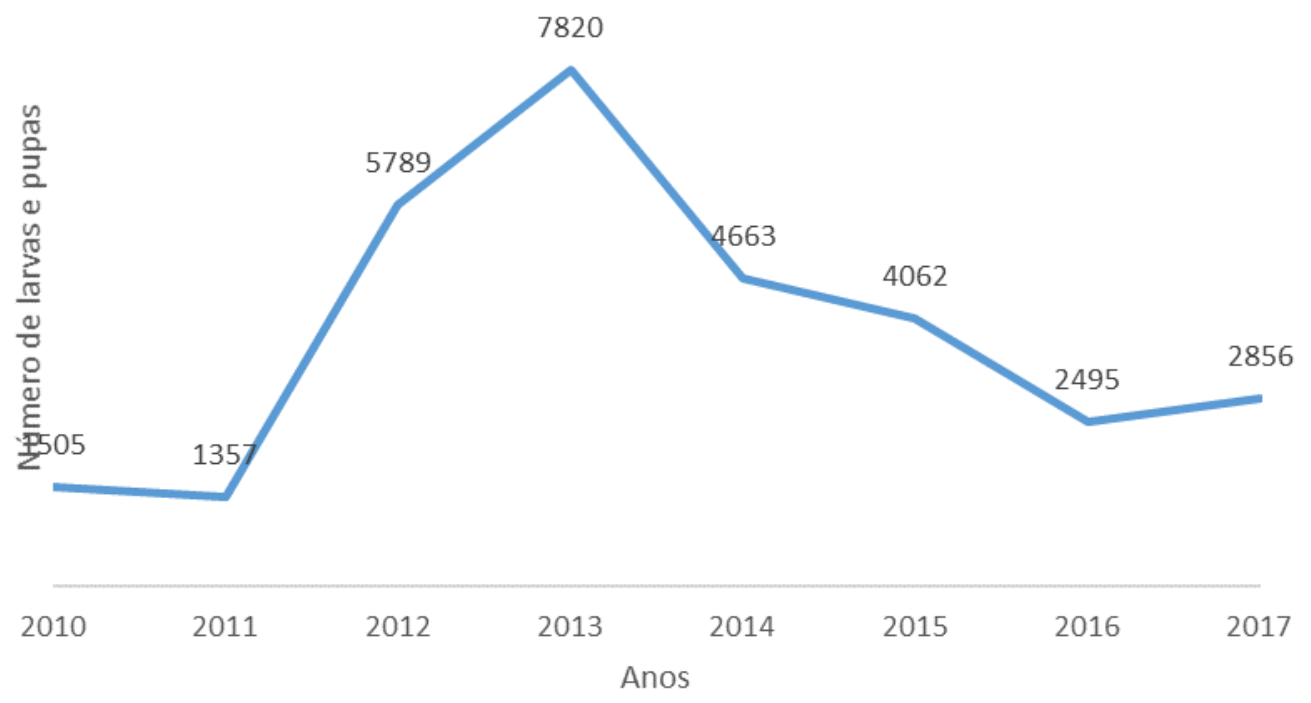

Fonte: DIVE, 2018. Org. pelos autores.

Observa-se um padrão na flutuação populacional do $A$. aegypti ao longo da série histórica, organizada por SE (Figura 3). Em todos os anos, o número de formas aquáticas apresenta crescente aumento nos meses de setembro a maio. Já nos meses de junho a agosto, tende a cair. Esse padrão sugere que a infestação sofre picos pela sazonalidade.

Figura 3: Flutuação populacional das formas aquáticas (larvas e pupas) de A. aegypti, por semana epidemiológica (SE), entre os anos de 2010 a 2017

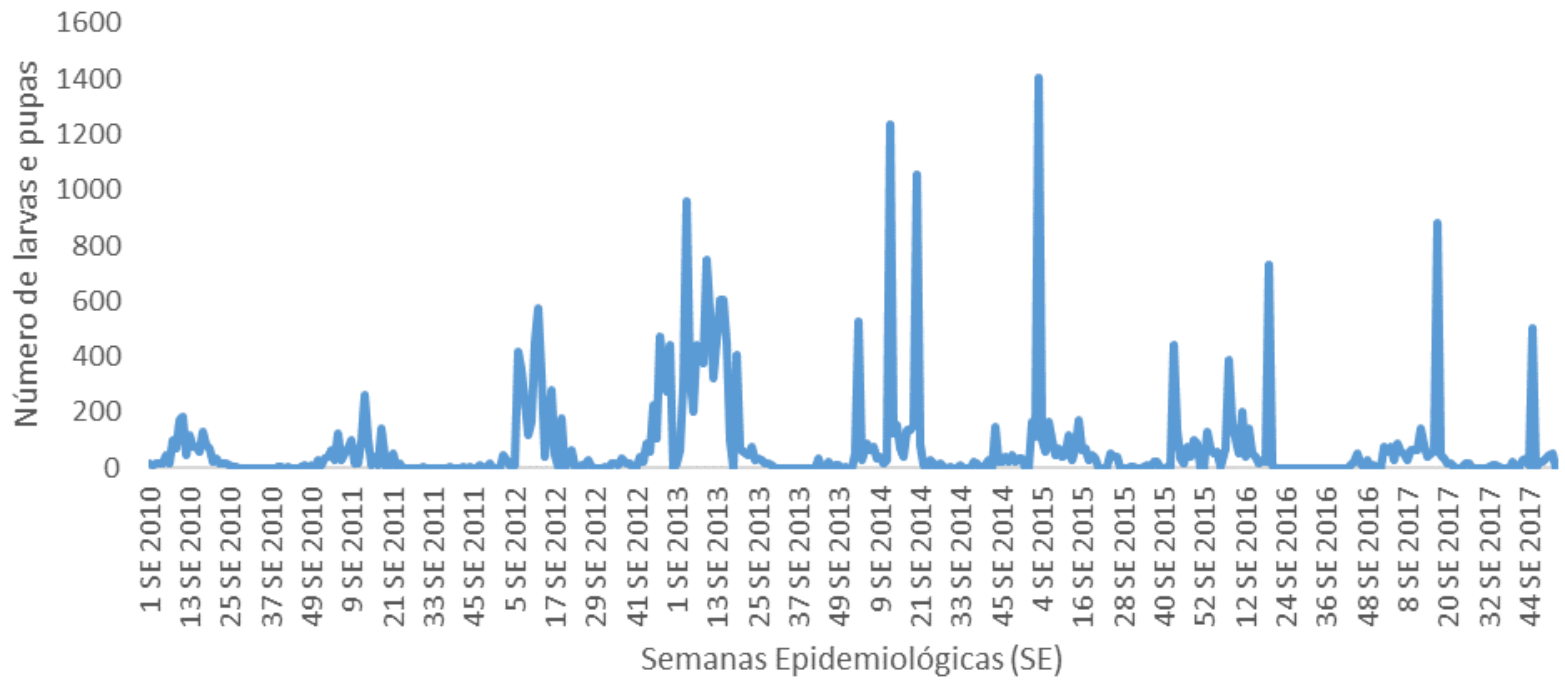

Fonte: DIVE, 2018. Org. pelos autores. 
$\mathrm{Na}$ Figura 4, formas aquáticas foram agrupadas por estações do ano, evidenciando o aumento nas estações mais quentes do ano e sua diminuição nas estações com baixas temperaturas. O verão foi a estação do ano que mais registrou número de formas aquáticas, a média foi de 174,5 larvas e pupas, enquanto o inverno foi a estação do ano com menos registros, média de 6,0.

Figura 4: Média do número de larvas e pupas registrados por estações do ano, 2010 a 2017

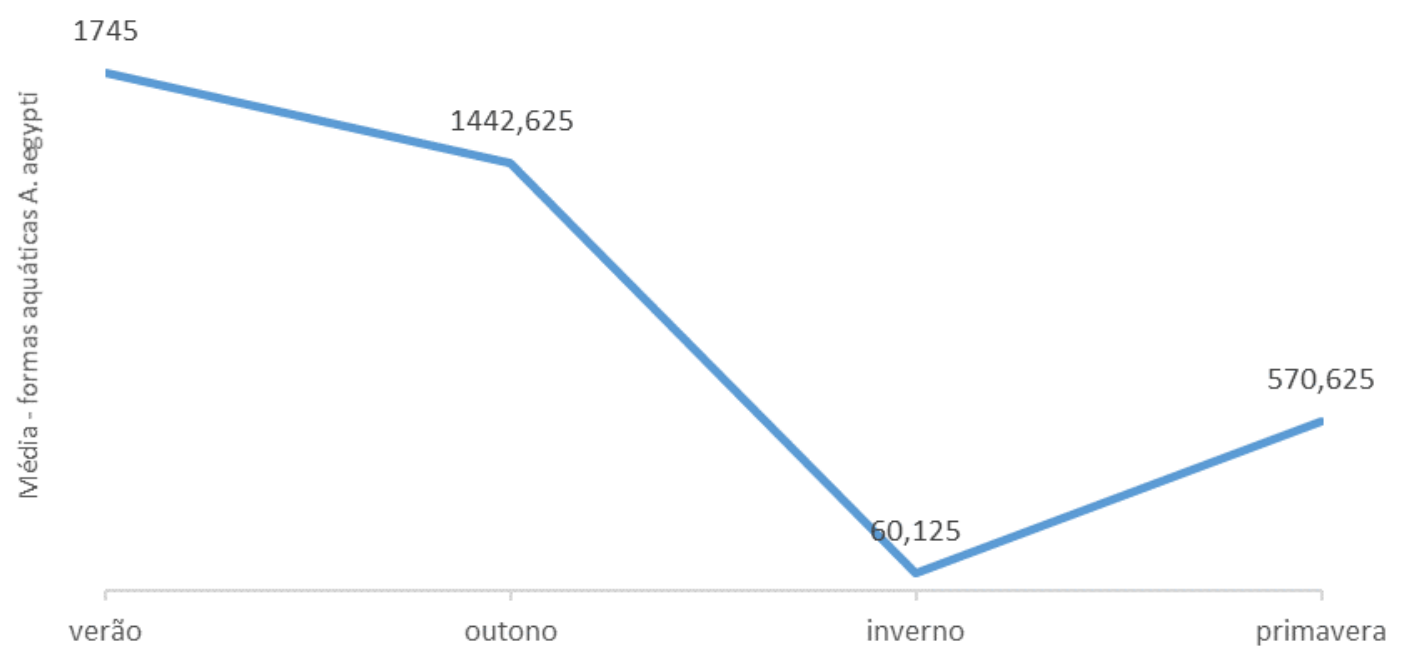

Fonte: DIVE, 2018. Org. pelos autores.

Em todos os anos aqui estudados, o $A$. aegypti apresenta picos de crescimentos nos meses mais quentes e volta a cair nos meses mais frios. Neste sentido, a análise do comportamento das médias da temperatura e precipitação, nas estações da primavera e verão, e o aumento dos números de mosquito, indicam ser um aspecto que deverá ser analisado com mais cuidado nesta pesquisa adiante.

Os dados disponibilizados por MERRA2, referentes aos registros das temperaturas médias máximas e médias mínimas deixam bem caracterizadas as estações do ano no município de Chapecó (Figura $5)$.

Figura 5: Evolução diária da temperatura média máxima (TMAX), temperatura média mínima (TMIN) e precipitação (PREC), no município de Chapecó, 2010 a 2017

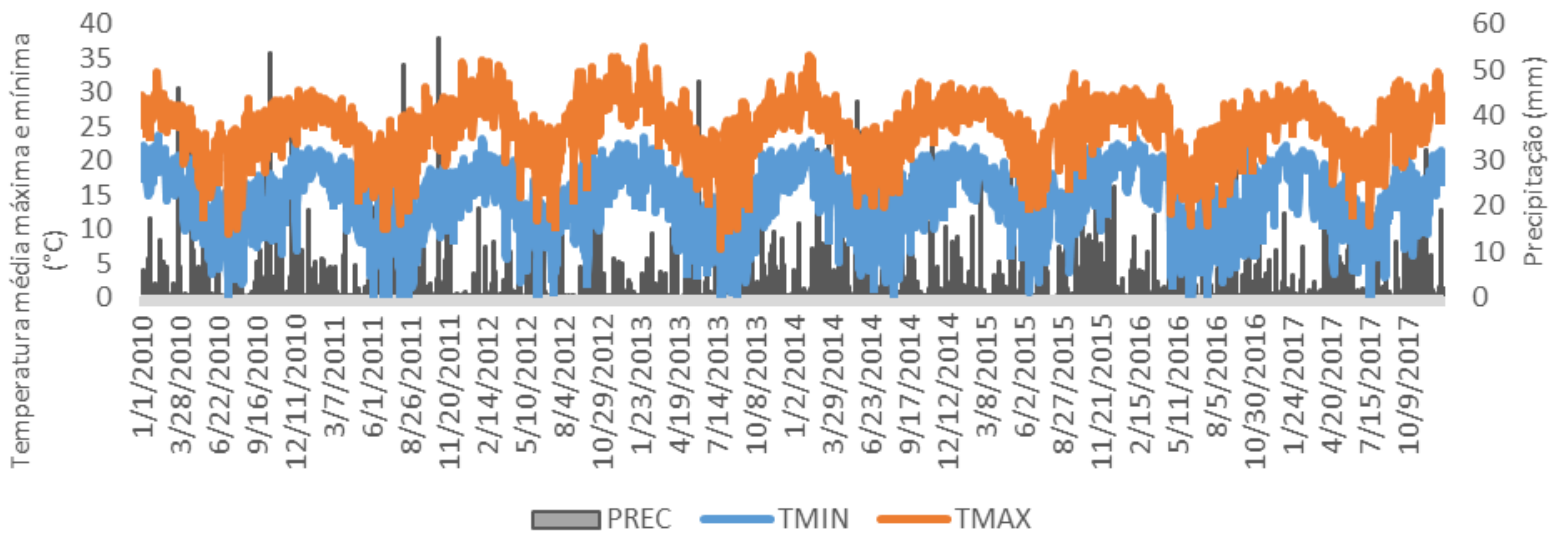

Fonte: DIVE, 2018; MERRA2, 2018. Org. pelos autores. 
Os meses de primavera (TMIN entre $14,1^{\circ} \mathrm{C}$ e $17,3^{\circ} \mathrm{C}$ e $\operatorname{TMAX}$ entre $25,4{ }^{\circ} \mathrm{C}$ e $28,8^{\circ} \mathrm{C}$ ) e verão (TMIN $18,1^{\circ} \mathrm{C}$ e $19,3{ }^{\circ} \mathrm{C}$ e $\operatorname{TMAX} 27,5^{\circ} \mathrm{C}$ e $30^{\circ} \mathrm{C}$ ) foram caracterizados pelo aumento da temperatura. $\mathrm{O}$ ano de 2012 foi o ano com as médias de temperaturas máximas mais elevadas para o verão e primavera.

Os meses de outono (TMIN entre $11^{\circ} \mathrm{C}$ e $13,3^{\circ} \mathrm{C}$ e TMAX entre $21,7^{\circ} \mathrm{C}$ e $24^{\circ} \mathrm{C}$ ) e inverno (TMIN entre $9,3^{\circ} \mathrm{C}$ e $12,2^{\circ} \mathrm{C}$ e TMAX entre $20,5^{\circ} \mathrm{C}$ e $23,4^{\circ} \mathrm{C}$ ) foram caracterizados pela diminuição das temperaturas, seguindo esse padrão.

Com relação a precipitação, média diária no verão, ficou entre $1 \mathrm{~mm}$ a $2,5 \mathrm{~mm}$, na primavera entre $1,2 \mathrm{~mm}$ e $3,8 \mathrm{~mm}$, outono entre $0,5 \mathrm{~mm}$ e $3,3 \mathrm{~mm}$ e inverno entre $0,5 \mathrm{~mm}$ e $2,9 \mathrm{~mm}$.

A estação do ano que acumulou a maior quantidade de precipitação, durante os anos estudados, foi a primavera, seguida do outono, inverno e verão com o menor acumulado.

No entanto, quando se compara a dinâmica populacional do $A$. aegypti com estas variáveis, encontrase os seguintes dados:

Figura 6: Relação dos fatores climáticos com o A. aegypti (larvas e pupas) por estações do ano, no município de Chapecó, entre os anos de 2010 e 2017

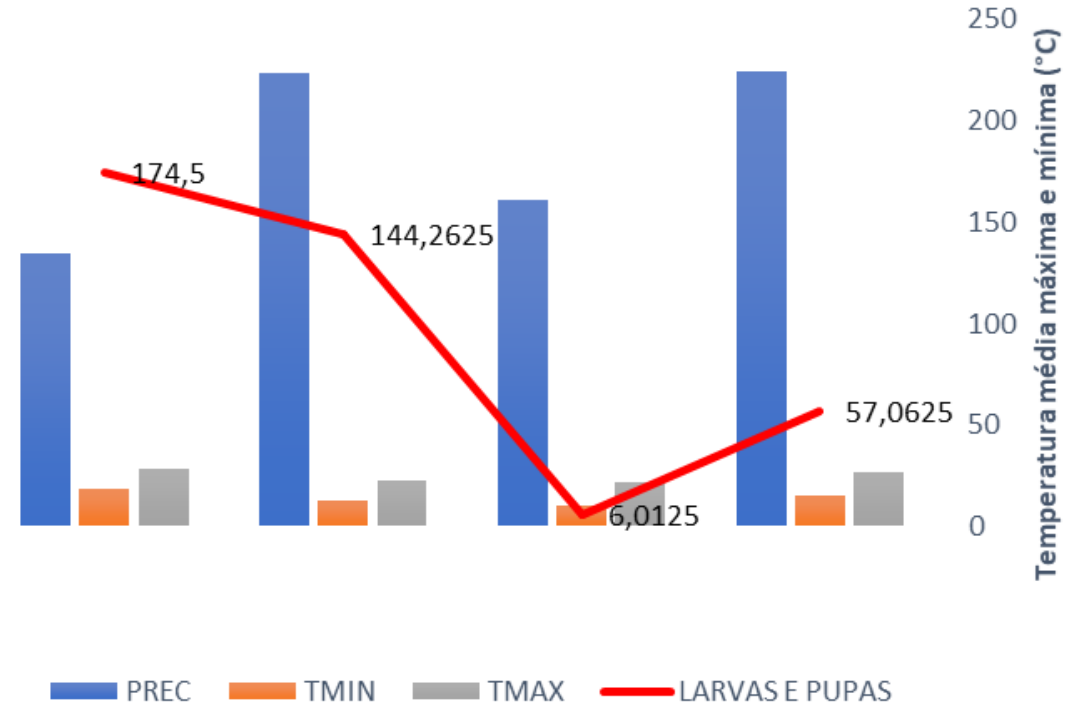

Fonte: DIVE, 2018; MERRA2, 2018. Org. pelos autores.

A Figura 6 apresenta o perfil dos valores médios TMAX, TMIN e PREC por estação do ano para o município de Chapecó com a flutuação da população de $A$. aegypti (larvas e pupas). Nela é possível observar que não existe uma estação seca, o verão e inverno apresentam menores médias de PREC, respectivamente. É na primavera e no outono que encontramos as estações com um bom regime de chuva (as médias maiores estão na primavera). Padrão típico de Cfa (Koppen). Correlacionando com as médias, pode-se observar que a flutuação do $A$. aegypti em Chapecó tem ciclo bastante marcado pelas altas temperatura do verão e outono, sendo que não se não identificou uma relação ou comportamento tendencioso forte desses fenômenos com a precipitação. No entanto, os valores médios não mostram a tendência de aumento ou diminuição da população de $A$. aegypti, uma vez que se verificou a ocorrência de anomalias positivas (2013 e 2014) nas médias.

Todavia, com as informações das médias de TMAX, TMIN e PREC por estação, pode-se inferir que houve relação entre a anomalia climática (2013 e 2014) e a flutuação da população de $A$. aegypti, como podemos observar na Tabela 1. 
Tabela 1: Relação das médias de TMIN e TMAX, acumulado da PREC. e soma de $A$. aegypti por estações do ano, entre os anos de 2010 a 2017

\begin{tabular}{|c|c|c|c|c|c|c|c|c|}
\hline ANO & ESTAÇÃO & DATA & TMIN & TMAX & PREC & ovos & LARVAS/PUPAS & ADULTOS \\
\hline \multirow{4}{*}{2010} & verão & $\begin{array}{l}01 / 01 / 10 \text { a } \\
19 / 03 / 10\end{array}$ & 18,9 & 27,6 & 123,4 & 0 & 667 & 4 \\
\hline & outono & $\begin{array}{l}20 / 03 / 10 \text { a } \\
20 / 06 / 10\end{array}$ & 12,6 & 21,9 & 254,8 & 0 & 757 & 13 \\
\hline & inverno & $\begin{array}{l}21 / 06 / 10 a \\
22 / 09 / 10\end{array}$ & 10,1 & 21,6 & 85,5 & 0 & 11 & 0 \\
\hline & primavera & $\begin{array}{l}23 / 09 / 10 \text { a } \\
20 / 12 / 10\end{array}$ & 14,1 & 25,4 & 273 & 0 & 55 & 0 \\
\hline \multirow{4}{*}{2011} & verão & $\begin{array}{l}21 / 12 / 10 a \\
19 / 03 / 11\end{array}$ & 18,6 & 27,8 & 164,6 & 0 & 592 & 11 \\
\hline & outono & $\begin{array}{l}20 / 03 / 11 \text { a } \\
20 / 06 / 11\end{array}$ & 12,5 & 22,6 & 130,5 & 0 & 737 & 0 \\
\hline & inverno & $\begin{array}{l}21 / 06 / 11 \text { a } \\
22 / 09 / 11\end{array}$ & 10,0 & 20,5 & 272,5 & 0 & 5 & 0 \\
\hline & primavera & $\begin{array}{l}23 / 09 / 11 \text { a } \\
21 / 12 / 11\end{array}$ & 14,3 & 25,9 & 156,7 & 0 & 38 & 0 \\
\hline \multirow{4}{*}{2012} & verão & $\begin{array}{l}22 / 12 / 11 \text { a } \\
19 / 03 / 12\end{array}$ & 18,1 & 30,0 & 107,3 & 0 & 1922 & 5 \\
\hline & outono & $\begin{array}{l}20 / 03 / 12 \text { a } \\
19 / 06 / 12\end{array}$ & 11,7 & 23,6 & 205,6 & 0 & 1609 & 0 \\
\hline & inverno & $\begin{array}{l}20 / 06 / 12 \text { a } \\
21 / 09 / 12\end{array}$ & 11,6 & 23,3 & 96,2 & 0 & 141 & 0 \\
\hline & primavera & $\begin{array}{l}22 / 09 / 12 \text { a } \\
20 / 12 / 12\end{array}$ & 16,6 & 28,8 & 217 & 0 & 2117 & 0 \\
\hline \multirow{4}{*}{2013} & verão & $\begin{array}{l}21 / 12 / 12 \text { a } \\
19 / 03 / 13\end{array}$ & 18,1 & 29,0 & 90 & 0 & 4517 & 7 \\
\hline & outono & $\begin{array}{l}20 / 03 / 13 \text { a } \\
20 / 06 / 13\end{array}$ & 12,2 & 23,5 & 291,2 & 0 & 3158 & 0 \\
\hline & inverno & $\begin{array}{l}21 / 06 / 13 \text { a } \\
21 / 09 / 13\end{array}$ & 9,3 & 20,6 & 177,9 & 40 & 70 & 0 \\
\hline & primavera & $\begin{array}{l}22 / 09 / 13 \text { a } \\
20 / 12 / 13\end{array}$ & 14,8 & 25,9 & 219,2 & 1616 & 75 & 0 \\
\hline \multirow[t]{2}{*}{2014} & verão & $\begin{array}{l}21 / 12 / 13 \mathrm{a} \\
19 / 03 / 14\end{array}$ & 18,9 & 29,4 & 226,3 & 38602 & 2023 & 0 \\
\hline & outono & $20 / 03 / 14 a$ & 13,2 & 23,0 & 306,3 & 21283 & 2156 & 6 \\
\hline
\end{tabular}




\begin{tabular}{|c|c|c|c|c|c|c|c|c|}
\hline ANO & ESTAÇÃO & DATA & TMIN & TMAX & PREC & ovos & LARVAS/PUPAS & ADULTOS \\
\hline & $\begin{array}{l}\text { inverno } \\
\text { primavera }\end{array}$ & $\begin{array}{l}20 / 06 / 14 \\
21 / 06 / 14 \text { a } \\
21 / 09 / 14 \\
22 / 09 / 14 \text { a } \\
20 / 12 / 14\end{array}$ & $\begin{array}{l}11,1 \\
16,5\end{array}$ & $\begin{array}{l}21,9 \\
27,5\end{array}$ & $\begin{array}{c}230 \\
198,2\end{array}$ & $\begin{array}{r}244 \\
8471\end{array}$ & $\begin{array}{r}69 \\
415\end{array}$ & $\begin{array}{l}0 \\
0\end{array}$ \\
\hline \multirow{4}{*}{2015} & verão & $\begin{array}{l}21 / 12 / 14 \mathrm{a} \\
19 / 03 / 15\end{array}$ & 19,0 & 27,9 & 159,1 & 0 & 2302 & 0 \\
\hline & outono & $\begin{array}{l}20 / 03 / 15 \text { a } \\
20 / 06 / 15\end{array}$ & 13,3 & 24,0 & 159,6 & 0 & 685 & 0 \\
\hline & inverno & $\begin{array}{l}21 / 06 / 15 \text { a } \\
22 / 09 / 15\end{array}$ & 12,2 & 22,8 & 231,6 & 0 & 129 & 0 \\
\hline & primavera & $\begin{array}{l}23 / 09 / 15 a \\
21 / 12 / 15\end{array}$ & 17,3 & 26,4 & 342,8 & 0 & 946 & 0 \\
\hline \multirow{4}{*}{2016} & verão & $\begin{array}{l}22 / 12 / 15 \text { a } \\
19 / 03 / 16\end{array}$ & 19,3 & 27,5 & 117,8 & 0 & 1287 & 0 \\
\hline & outono & $\begin{array}{l}20 / 03 / 16 \text { a } \\
19 / 06 / 16\end{array}$ & 12,1 & 21,7 & 204,6 & 0 & 1068 & 0 \\
\hline & inverno & $\begin{array}{l}20 / 06 / 15 a \\
21 / 09 / 16\end{array}$ & 9,8 & 21,1 & 141,5 & 0 & 0 & 0 \\
\hline & primavera & $\begin{array}{l}22 / 09 / 16 \text { a } \\
20 / 12 / 16\end{array}$ & 14,6 & 25,7 & 107,8 & 0 & 140 & 0 \\
\hline \multirow{4}{*}{2017} & verão & $\begin{array}{l}21 / 12 / 16 \mathrm{a} \\
19 / 03 / 17\end{array}$ & 19,1 & 28,1 & 90,9 & 0 & 650 & 0 \\
\hline & outono & $\begin{array}{l}20 / 03 / 17 \text { a } \\
20 / 06 / 17\end{array}$ & 13,3 & 23,4 & 232,2 & 0 & 1371 & 0 \\
\hline & inverno & $\begin{array}{l}21 / 06 / 17 \text { a } \\
21 / 09 / 17\end{array}$ & 11,0 & 23,4 & 51,1 & 0 & 56 & 0 \\
\hline & primavera & $\begin{array}{l}22 / 09 / 17 \text { a } \\
20 / 12 / 17\end{array}$ & 15,3 & 26,9 & 278,8 & 0 & 779 & 0 \\
\hline
\end{tabular}

Fonte: DIVE, 2018; MERRA2, 2018. Org. pelos autores.

A TMIN $\left(14,1^{\circ} \mathrm{C}\right.$ entre $\left.17,3^{\circ} \mathrm{C}\right)$ e $\operatorname{TMAX}\left(25,4^{\circ} \mathrm{C}\right.$ entre $\left.28,8^{\circ} \mathrm{C}\right)$ na primavera, TMIN $\left(9,3^{\circ} \mathrm{C}\right.$ entre $\left.11,6^{\circ} \mathrm{C}\right)$ e TMAX $\left(20,5^{\circ} \mathrm{C}\right.$ entre $\left.23,4^{\circ} \mathrm{C}\right)$ no inverno, demonstram ter maior correlação com as formas aquáticas do $A$. aegypti. Já com a PREC, o acumulado entre $90,9 \mathrm{~mm}$ e $226,3 \mathrm{~mm}$ no verão, mostrou maior correlação com as formas de ovos e o acumulado entre $130,5 \mathrm{~mm}$ e $306,3 \mathrm{~mm}$ no outono com as formas aquáticas (Tabela 2).

Para a ocorrência do pico de 7.820 formas aquáticas em 2013, destaca-se que houve um aumento da temperatura máxima e mínima no inverno e primavera de 2012, impactando o verão de 2013. Isto pode ser verificado na correlação estatística, conforme se observa na Tabela 2. 
Infere-se um dado sobre a precipitação na passagem das estações primavera - verão de 2011 2012. Na primavera de 2011 a média de precipitação $(156 \mathrm{~mm})$ ficou abaixo da média $(204,25 \mathrm{~mm})$ do conjunto de anos avaliados, o que pode ter impactado nos dados de infestação no verão de 2012 $(107,3 \mathrm{~mm})$ que por sua vez, registrou valores menores que o padrão (134,92 mm). Este dado se repete na primavera de 2016 e no verão de 2017.

Tabela 2: Correlação de Spearman das médias de TMIN e TMAX, acumulado de PREC. e soma de A. aegypti, separados por estações do ano, município de Chapecó, 2010 a 2017

\begin{tabular}{llccc}
\hline Estação do ano & $\boldsymbol{A}$. aegypti & TMIN & TMAX & PREC \\
\hline \multirow{2}{*}{ Verão } & Formas Aquáticas & $-0,56$ & 0,50 & $-0,13$ \\
\cline { 2 - 5 } & Ovos & 0,16 & 0,42 & 0,80 \\
\hline \multirow{2}{*}{ Outono } & Formas Aquáticas & $-0,22$ & 0,35 & 0,74 \\
& Ovos & 0,38 & 0,02 & 0,55 \\
\hline \multirow{2}{*}{ Inverno } & Formas Aquáticas & 0,75 & 0,68 & $-0,01$ \\
\cline { 2 - 5 } primavera & Ovos & 0,09 & $-0,08$ & 0,37 \\
\hline & Formas Aquáticas & 0,71 & 0,88 & 0,30 \\
\cline { 2 - 4 } & Ovos & 0,32 & 0,29 & $-0,15$ \\
\hline
\end{tabular}

Fonte: DIVE, 2018; MERRA2, 2018. Org. pelos autores.

Nesta análise, o coeficiente de correlação pode variar em termos de valor de $-1 \mathrm{a}+1$. Quanto maior for o valor absoluto do coeficiente, mais forte é a relação entre as variáveis. Desta forma, os valores para TMIN e TMAX no inverno $(0,75$ e 0,68$)$ e na primavera $(0,71$ e 0,88$)$ se mostraram com uma alta relação entre estas variáveis, confirmando a hipótese de que as variáveis em tela estão associadas a flutuação de $A$. aegypti monitorados pela DIVE.

\section{CONCLUSÃO}

A flutuação populacional de $A$. aegypti, em Chapecó, mantem um padrão de aumento no crescimento nos meses mais quentes, diminuindo nos meses mais frios, indicando assim, relação da infestação com a sazonalidade.

Chama-se atenção para o comportamento destas variáveis para a primavera. Na literatura, a flutuação de $A$. aegypti tem um ciclo bastante marcado pelas altas temperatura do verão e outono, mas para os casos de Chapecó, não se identificou uma relação ou comportamento tendencioso forte desses fenômenos com a precipitação nestas estações do ano.

Identificou-se um pico de número de larvas e pupas registrados em 2013, impactado por uma primavera quente do ano anterior e um verão quente acima da média. A associação entre uma primavera de 2012 acima da média tanto para as médias das temperaturas mínimas e máximas (acima da média de $16{ }^{\circ} \mathrm{C}$ e de $25{ }^{\circ} \mathrm{C}$, respectivamente) e a média da temperatura máxima no verão de 2013 (acima da média $30 \stackrel{\circ}{\circ}$ ) quente com uma estação chuvosa na primavera (média acima de $200 \mathrm{~mm}$ ) mostrou-se como condição climática favorável para o aumento da flutuação da população deste referido ano.

Com uma precipitação abaixo da média associada com temperatura máxima de $25^{\circ} \mathrm{C}$ na primavera 2011 mostrou uma relação no verão de 2012, com uma baixa infestação. A passagem da primavera 2012 -2013, por outro lado, com altas temperatura, nas duas estações, sendo com alta precipitação na primavera, impactou nos maiores indicadores de infestação no verão de 2013. Ressalta-se que o verão de 2013 registrou os menores valores de precipitação $(90 \mathrm{~mm})$.

Todavia, para o ano de 2014, o comportamento da primavera de 2013 não se repetiu como no ano de 2012, assim, apesar do indicador da população flutuante ainda ser alto (4.663), a TMAX da primavera de 2013 registrou o comportamento padrão $\left(25^{\circ} \mathrm{C}\right)$ e a média da TMAX do verão 2014 ficou mais ameno $\left(29^{\circ} \mathrm{C}\right)$. Em 2015 ainda que a primavera registrou estar acima da média, o verão estava abaixo. Os dados para 2016 e 2017 apontam para esta mesma tendência. 
Para a relação dos fatores climáticos com o $A$. aegypti, o uso de dados de MERRA2 se mostrou eficiente e oportuno nas pesquisas que envolvam clima e doenças proliferadas pelo mosquito $A$. aegypti, pois além de fornecer uma série de dados sem falhas, possibilita a aquisição de dados em áreas que possuem escassez de estações meteorológicas.

O elevado número de $A$. aegypti registrados, ao longo dos anos, aponta que em uma epidemia de vírus transmitidos por esse vetor, o risco de contaminação da população é preocupante. Entendemos que os fatores ambientais favorecem a proliferação do vetor, como as condições climáticas e presença de água, porém, o processo de urbanização em que os ambientes naturais são substituídos por artificias, o acúmulo de resíduos oriundos desses processos e a ação antrópica, também influenciam, portanto, os fatores socioeconômicos também precisam ser analisados. Estes serão os próximos passos da pesquisa.

\section{REFERÊNCIAS}

BRAGA, Ima Aparecida; VALLE, Denise. Aedes aegypti: histórico do controle no Brasil. Epidemiologia e serviços de saúde, v. 16, n. 2, p. 113-118, 2007.

https://doi.org/10.5123/S1679-49742007000400007

BRASIL. Ministério da Saúde. Secretaria de Vigilância em Saúde. Dengue: diagnóstico e manejo clínico: adulto e criança. 5. ed. - Brasília: Ministério da Saúde, 2016. 58 p.: il. ISBN 978-85-3342344-2.

CÂMARA, Fernando Portela et al. Clima e epidemias de dengue no Estado do Rio de Janeiro. Rev Soc Bras Med Trop, v. 42, n. 2, p. 137-40, 2009. https://doi.org/10.1590/S0037$\underline{86822009000200008}$

CONSOLI, Rotraut AGB; DE OLIVEIRA, Ricardo Lourenço. Principais mosquitos de importância sanitária no Brasil. SciELO-Editora FIOCRUZ, 1994. https://doi.org/10.7476/9788575412909

DIVE - Diretoria de Vigilância Epidemiológica de Santa Catarina. Dados atualizados sobre o número de focos e casos notificados no estado. Disponível: $<$ http://www.dive.sc.gov.br/index.php/d-a/item/dengue> Acesso: set. 2018a.

DIVE - Diretoria de Vigilância Epidemiológica de Santa Catarina. Boletim Epidemiológico $\mathbf{n}^{\circ}$ 05/2019 Vigilância entomológica do Aedes aegypti e situação epidemiológica de dengue, febre de chikungunya e zika vírus em Santa Catarina. Santa Catarina. Disponível: $<$ http://www.dive.sc.gov.br/conteudos/boletim2019/Bolet05Dengue/Boletimn05denguechikungunyaezi kaSE08.pdf> Acesso: mar. 2019.

DIVE - Diretoria de Vigilância Epidemiológica de Santa Catarina. Dengue: Orientações Técnicas para Pessoal de Campo. Santa Catarina: Florianópolis, 2018b.

FEITOSA, Flávia Regina Sobral; SOBRAL, Ivana Silva; DE JESUS, Edilma Nunes. Indicadores Socioambientais como subsídio à prevenção e controle da Dengue. Electronic Journal of Management, Education and Environmental Technology (REGET), v. 19, n. 3, p. 351-368, 2015.

FERREIRA, Helio Henrique et al. Avaliação Espacial da Dengue na Área Urbana de Itu-São Paulo. Revista do Departamento de Geografia, v. 33, p. 106-116, 2017. https://doi.org/10.11606/rdg.v33i0.128515

GELARO, Ronald et al. The modern-era retrospective analysis for research and applications, version 2 (MERRA-2). Journal of Climate, v. 30, n. 14, p. 5419-5454, 2017. https://doi.org/10.1175/JCLI-D16-0758.1

HINO, Paula et al. Evolução temporal da dengue no município de Ribeirão Preto, São Paulo, 1994 a 2003. Ciência \& Saúde Coletiva, v. 15, p. 233-238, 2010. https://doi.org/10.1590/S1413$\underline{81232010000100028}$

IBGE - Instituto Brasileiro de Geografia e Estatística. Base Cartográfica Digital. 2019. Disponível em: https://downloads.ibge.gov.br/index.htm. Acesso jul. 2019.

LIMA, Suely Franco Siqueira; BARROZO, Ligia Vizeu; MATAVELI, Guilherme Augusto Verola. Temperatura da Superfície e Precipitação que Influenciam na Incidência do Aedes Aegypti em São 
Paulo. Revista do Departamento de Geografia, p. 174-183, 2018.

https://doi.org/10.11606/rdg.v0ispe.145697

OLIVEIRA, Cássia. Calor e chuva: ambiente preferido do Aedes Aegypti. Jornal IBIA, [online], atualizado em 28/09/2018. Disponível: https://jornalibia.com.br/noticias/saude/calor-e-chuvaambiente-preferido-do-aedes-aegypti/ Acesso: 19 nov. 2018.

PENNA, Brunna Romero. Impacto dos aerossóis na reanálise Merra-Z. São José dos Campos: INPE, 2018. sid.inpe.br/mtc-m21c/2018/05.02.18.16-TDI. Disponível: <http://urlib.net/8JMKD3MGP3W34R/3R35M4H> Acesso: nov. 2018.

RIBEIRO, Andressa F. et al. Associação entre incidência de dengue e variáveis climáticas. Revista de Saúde Pública, v. 40, p. 671-676, 2006. https://doi.org/10.1590/S0034-89102006000500017

SALVI, Fabíola Inês; LUTINSKI, Junir Antonio; BUSATO, Maria Assunta. Flutuação populacional de Aedes aegypti (Diptera: Culicidae) e medidas de controle no município de Chapecó. NBC-Periódico Científico do Núcleo de Biociências, v. 8, n. 16.

SILVA, Jeziel Souza; MARIANO, Zilda de Fátima; SCOPEL, Irací. A influência do clima urbano na proliferação do mosquito Aedes aegypti em Jataí (GO), na perspectiva da geografia médica. Hygeia, v. 3, n. 5, 2007.

SOUZA, Sócrates Siqueira de; SILVA, lonizete Garcia da; SILVA, Heloísa Helena Garcia da. Associação entre incidência de dengue, pluviosidade e densidade larvária de Aedes aegypti, no Estado de Goiás. Rev Soc Bras Med Trop, p. 152-155, 2010. https://doi.org/10.1590/S0037$\underline{86822010000200009}$

VIANA, Dione Viero; IGNOTTI, Eliane. A ocorrência da dengue e variações meteorológicas no Brasil: revisão sistemática. Revista Brasileira de Epidemiologia, v. 16, p. 240-256, 2013.

https://doi.org/10.1590/S1415-790X2013000200002

WHO - WORLD HEALTH ORGANIZATION. Dengue Control. Disponível:

$<$ https://www.who.int/denguecontrol/disease/en/> Acesso: ago. 2018. 